\title{
Detection of Herpesviruses 1-6 and Community-Acquired Respiratory Viruses in Patients with Chronic Rhinosinusitis with Nasal Polyposis
}

\author{
Cristina Costa $^{a}$ Massimiliano Garzaro $^{\mathrm{b}}$ Valeria Boggio $^{\mathrm{b}}$ Francesca Sidoti $^{\mathrm{a}}$ \\ Salvatore Simeone ${ }^{a}$ Luca Raimondo ${ }^{b}$ Giovanni Patrick Cavallo ${ }^{b}$ \\ Giancarlo Pecorarib $^{b}$ Rossana Cavallo ${ }^{a}$ \\ ${ }^{a}$ Microbiology and Virology Unit and b First ENT Division, Città della Salute e della Scienza Hospital, \\ University of Turin, Turin, Italy
}

\section{Key Words}

Cytomegalovirus · Epstein-Barr virus · Human herpesvirus 6 . Community-acquired respiratory viruses . Nasal polyposis .

Functional endoscopic sinus surgery

\section{Abstract}

Objective: To evaluate the prevalence of human herpesviruses (HHV) 1-6 and community-acquired respiratory viruses (CARVs) in specimens from patients with nasal polyposis undergoing functional endoscopic sinus surgery (FESS) and investigate the potential clinical role. Methods: Viral occurrence was evaluated by molecular methods in polyp, turbinate mucosa, and pre-and postoperative scraping specimens from 35 consecutive patients at different time points in relation to FESS. Results: Overall, 21 patients (60\%) were positive to at least one virus in at least one specimen; in particular, $12.1 \%$ of all specimens for HHV- 6 (3/35 polyps, $11 / 31$ turbinates, 1 presurgical scraping) and $10.5 \%$ for Epstein-Barr virus (EBV) (8/35 polyps, 3/31 turbinates, $1 / 29$ pre- and 1/29 postsurgical scraping), followed by CMV and HSV-1 (both $1.6 \% ; 1 / 35$ polyps, $1 / 29$ postsurgical scraping and $2 / 35$ polyps, respectively). EBV positivity tended to be higher in polyps, as well as HHV-6 in adjacent healthy turbinate mucosa, although no significant association was found. Only one preoperative cytological specimen was positive to parainfluenza virus-1. Conclusion: No association between the development of nasal polyps, herpesviruses and CARVs seems to exist. However, the higher EBV frequency in polyps could suggest a causative role or persistence in the inflammatory lymphoid tissue.

C) 2014 S. Karger AG, Basel

\section{Introduction}

Nasal polyps are a common chronic disease of nasal and paranasal sinus mucosa, which affects approximately $4 \%$ of general population. These benign lesions are characterized by inflammation-induced mucosal swelling, inflammatory cell infiltration, and subepithelial edema. Nasal polyps are usually associated with chronic rhinosinusitis with nasal polyps (CRSwNP) and most common symptoms are obstruction, rhinorrhea, anosmia, facial

C.C. and M.G. contributed equally to this study and share first authorship.

\section{KARGER}

E-Mail karger@karger.com

www.karger.com/int
(C) 2014 S. Karger AG, Basel

$0300-5526 / 14 / 0572-0101 \$ 39.50 / 0$
Cristina Costa, MD, $\mathrm{PhD}$

Microbiology and Virology Unit

Città della Salute e della Scienza Hospital, University of Turin

Via Santena 9, IT-10126 Turin (Italy)

E-Mail cristina.costa@ unito.it 
pain and headache [1]. Medical therapy consists of intranasal steroids [2] and antibiotics [3]; nevertheless, functional endoscopic sinus surgery (FESS) is often necessary, despite a $70 \%$ chance of recurrence [4]. Pathogenesis and molecular mechanisms underlying CRSwNP are poorly known; several factors have been investigated, including Kirsten rat sarcoma (K-ras) codon 12 mutations/increased expression [5], elevated expression of vascular endothelial growth factor $\mathrm{A}$ and transforming growth factor- $\beta_{1}[6,7]$, as well as clinical features, including allergy, asthma, immunodeficiency and chronic sinus infections $[8,9]$. Viral infections have been hypothesized to play a role in the pathogenesis, progression and recurrence of CRSwNP [10]. While human papillomavirus has been associated rather to neoplastic lesions [11-13], very few studies have investigated the role of herpesviruses and community-acquired respiratory viruses (CARVs) with no definitive conclusions [14]. The Herpesviridae family encompasses several DNA viruses that are able to establish lifelong latent infections and reactivate in immunocompromised conditions; in particular, human herpesviruses (HHV) 1-6 (including HSV-1 and -2, VZV, Epstein-Barr virus (EBV), CMV) are highly seroprevalent and have been associated to upper airway infections.

The aim of this study was to evaluate human herpesviruses 1-6 and CARVs prevalence by molecular methods in nasal polyps, adjacent inferior/middle turbinates, and pre- and postoperative nasal scraping from patients undergoing FESS.

\section{Materials and Methods}

The study population consisted of 35 consecutive patients $(\mathrm{M} / \mathrm{F} 25 / 10$; mean age $\pm \mathrm{SD}, 50.3 \pm 15.4$ years; range $23-77)$ with CRSwNP undergoing FESS between September 2011 and April 2012 (table 1). All patients gave their informed consent and the study was approved by the institutional review board. Diagnosis of CRSwNP was made on the basis of European Position Paper on Rhinosinusitis and Nasal Polyps (EPOS) 2012 criteria [1]. In detail, diagnostic criteria included inflammation of the nose and the paranasal sinuses characterized by two or more symptoms, one of which being either nasal blockage/obstruction/congestion or nasal discharge (anterior/posterior nasal drip); facial pain/pressure; reduction/loss of smell for $\geq 12$ weeks; supported by endoscopic signs of nasal polyps, mucopurulent discharge, edema/mucosal obstruction and/or computed tomography changes. All patients were affected by CRSwNP with multiple polyps arising from the middle turbinate, middle meatus, or ethmoidal sinuses and were classified as grade II-III according to the Mackay and Lund system [15]. Pediatric subjects, HIV-seropositive individuals, patients with cystic fibrosis, immotile cilia syndrome, allergic fungal rhinosinusitis and inverted papilloma were excluded. The following time points were considered: $\mathrm{T}_{0}$ ( 1 month presurgery) clinical his-
Table 1. Demographic and clinical features of the study population

\begin{tabular}{lcc}
\hline Patients' characteristics & $\mathrm{n}($ total = 35) & $\%$ \\
\hline Male/female & $25 / 10$ & - \\
Mean age \pm SD, years & $50.3 \pm 15.4$ & - \\
Allergy & 15 & 42.9 \\
Asthma & 8 & 22.9 \\
Family anamnesis & & \\
$\quad$ Asthma/allergy & 10 & 28.6 \\
$\quad 3$ & 8.6 \\
Previous polyposis & 10 & 28.6 \\
Nasal obstruction (VAS 0-10) & & \\
$\quad$ 0-4 & 5 & 14.4 \\
$\quad$ - 8 & 15 & 42.8 \\
$\quad$ 9-10 & 15 & 42.8 \\
Anterior discharge & 20 & 57.1 \\
Posterior discharge & 13 & 37.1 \\
Loss of smell (any grade) & 32 & 31.4 \\
Facial pain & 11 & \\
\hline
\end{tabular}

tory for allergy and asthma (previous investigation by prick test) and preoperative cytological specimen; $\mathrm{T}_{1}$ (surgery) collection of two bioptic samples of polyps and the adjacent inferior/middle turbinates without polyposis; $\mathrm{T}_{2}$ ( 1 month postsurgery) postoperative cytological specimen (fig. 1). Polyp specimens were collected from maxillary or ethmoid sinus, depending on the involved site; scraping for cytological samples was performed on inferior/ middle turbinates. Due to missing sending or inadequacy, only 31 , 29 , and 29 turbinate pre- and postoperative scraping specimens were available, respectively, for an overall number of 124 samples for molecular testing.

For processing of mucosa tissues, specimens were incubated with $200 \mu$ lysis buffer (Tissue Lysis Buffer; Qiagen, Milan, Italy) by brief vortexing and heating at $100^{\circ}$ for 5 min twice, vortexed briefly again, then centrifuged for $1 \mathrm{~min}$ at 13,000 rpm at room temperature. Subsequently, a mechanical lysis step with the rotorstator homogenizer Tissue Ruptor was performed. A 200- $\mu \mathrm{l}$ aliquot of supernatant, as well as of nasal scraping, was subjected to nucleic acid extraction using the Nuclisens EasyMAG platform (bioMérieux, Marcy l'Etoile, France).

For herpesviruses 1-6 detection and quantification, real-time PCR was performed, using commercially available kits (Q-PCR Complete Kit; ELITech Group, Milan, Italy) following the manufacturer's instructions, and the 7500 Real-Time PCR System (Applied Biosystems, Monza, Italy). Target regions were glycoprotein D and G for HSV-1 and HSV-2, respectively, ORF 29 for VZV, EBNA 1 for EBV, exon 4 and UL 123 for CMV, and ORF 13R for HHV-6.

The occurrence of CARVs was investigated using a commercially available multiplex PCR assay according to the manufacturer's instructions (RV15 OneStep ACE Detection, Seeplex ${ }^{\circledR}$; Seegene, Seoul, Korea), targeting sequences of influenza A and B viruses, RSV type A and B, adenovirus, metapneumovirus, coronaviruses 229E/NL63 and OC43, parainfluenza viruses 1-4, rhinoviruses $\mathrm{A} / \mathrm{B} / \mathrm{C}$, enteroviruses, and bocaviruses $1 / 2 / 3 / 4$ and the MultiNA System (Shimadzu Corp. Italia, Milan, Italy). 
Table 2. Herpesviruses 1-6 detection and viral load on polyp, turbinate mucosa, and pre- and postoperative scraping specimens from patients with chronic rhinosinusitis with nasal polyps undergoing functional endoscopic sinus surgery

\begin{tabular}{|c|c|c|c|c|c|c|}
\hline Samples $(\mathrm{n}=124)$ & HSV-1 & HSV -2 & VZV & CMV & EBV & HHV-6 \\
\hline Polyps $(\mathrm{n}=35)$ & $\begin{array}{l}2(5.7 \%) \\
25 ; 19\end{array}$ & 0 & 0 & $\begin{array}{l}1(2.9 \%) \\
35\end{array}$ & $\begin{array}{l}8(22.9 \%) \\
157 \pm 197 \\
70\end{array}$ & $\begin{array}{l}3(8.6 \%) \\
16,580 \pm 28,076 \\
440\end{array}$ \\
\hline Turbinates $(\mathrm{n}=31)$ & 0 & 0 & 0 & 0 & $\begin{array}{l}3(9.7 \%) \\
23 \pm 3 \\
25\end{array}$ & $\begin{array}{l}11(35.5 \%) \\
705 \pm 1,264 \\
37\end{array}$ \\
\hline Presurgical scraping $(\mathrm{n}=29)$ & 0 & 0 & 0 & 0 & $\begin{array}{l}1(3.4 \%) \\
12\end{array}$ & $\begin{array}{l}1(3.4 \%) \\
4,400\end{array}$ \\
\hline Postsurgical scraping $(\mathrm{n}=29)$ & $\begin{array}{l}0 \\
2(1.6 \%)\end{array}$ & 0 & 0 & $\begin{array}{l}1(3.4 \%) \\
2(1.6 \%)\end{array}$ & $\begin{array}{l}1(3.4 \%) \\
20 \\
13(10.5 \%)\end{array}$ & $\begin{array}{l}0 \\
15(12.1 \%)\end{array}$ \\
\hline
\end{tabular}

The following data are reported for each virus: raw number and percentage; viral load as mean \pm SD and median when more than two specimens are positive; otherwise, single results. Viral load is expressed as copies $/ 10^{4}$ cells.

Fig. 1. Synopsis of specimen collection in

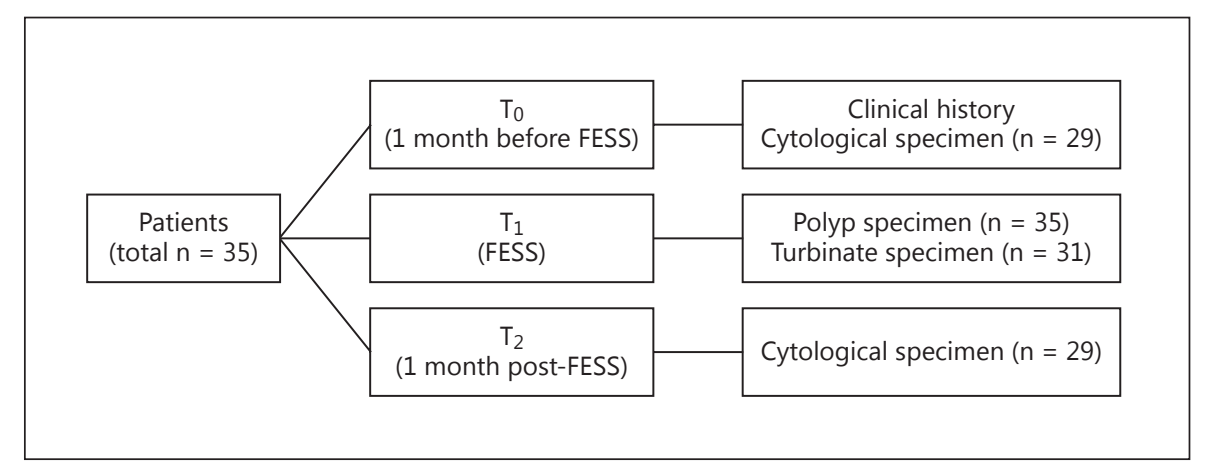
study population.

For statistical analysis, $\chi^{2}$ and Fisher's exact tests were applied, as appropriate. A p value $<0.05$ was considered statistically significant.

\section{Results}

The results are summarized in table 2 . Overall, $21 \mathrm{pa}-$ tients $(60 \%)$ were positive to at least one virus in at least one specimen. As regards herpesviruses 1-6, the highest prevalence was found for HHV-6 (15/124; 12.1\%; mean viral load $1,620 \pm 1,837$ copies $/ 10^{4}$ cells; median 820 ) and EBV (13/124; 10.5\%; mean viral load $88 \pm 140$; median 25), followed by CMV and HSV-1 (both 2/124; $1.6 \%)$. No specimen was positive to HSV-2 and VZV. In table 2, prevalence and viral load in different sites for each virus are reported. Viral load was $\leq 3 \times 10^{3}$ cop- ies $/ 10^{4}$ cells in all the cases, except for HHV-6 on a polyp specimen (see below). Considering the type of specimen, EBV was found in 8, 3 , and 2 polyp turbinate and cytological (one $\mathrm{T}_{0}$ and one $\mathrm{T}_{2}$ ) specimens, respectively. In 1 patient, EBV was positive in both polyp and turbinate specimens; in another individual, in polyp, turbinate and postoperative cytological samples. In both cases, the highest viral load was found in polyp specimens. HHV-6 was positive in 3 polyps, 11 turbinates, and one $\mathrm{T}_{0}$ scraping specimen. In 2 patients, both polyp and turbinate specimens were positive to $\mathrm{HHV}-6$, with the highest viral load being detected in the polyp sample $\left(49,000\right.$ copies $/ 10^{4}$ cells). HSV-1 was found in 2 polyp samples, 1 also positive to EBV. CMV was found in 1 polyp (also EBV-positive) and in a $\mathrm{T}_{2}$ scraping (other samples from the same patient were negative to herpesviruses 1-6). Although EBV positivity tended to be 
higher in polyps in comparison to other specimens, as well as HHV-6 in turbinate mucosa in comparison to other samples, no statistically significant association was found. Similarly, no significant association between EBV and HHV- 6 positivity on polyps and turbinate mucosa, respectively, and clinical features of allergy and asthma was found. As regardso CARVs, only one preoperative cytological specimen was positive to parainfluenza virus-1.

\section{Discussion}

In this study, the prevalence of herpesviruses 1-6 and CARVs in polyp, turbinate mucosa and nasal cytological specimens from patients undergoing FESS for CRSwNP was investigated.

Considering herpesviruses, the highest prevalence was found for HHV-6 (12.1\%, irrespective of the type of specimen), followed by EBV (10.5\%). CMV and HSV-1 prevalence was very low, while no specimen resulted positive for other herpesviruses. These results are different from those reported in previous studies. As regards EBV, old studies reported EBV-DNA qualitative detection by PCR in $80 \%$ of normal nasopharyngeal mucosa from Chinese subjects $[16,17]$. In another study on 13 nasal polyps, the same authors found EBV prevalence of 15,69 , and $85 \%$ using Southern blot hybridization, qualitative PCR, and in situ hybridization, respectively [18]; this study evidenced a highly different sensitivity with these different methods and led the author to hypothesize that nasal mucosa is a site where EBV persists through a low replicative level in resident lymphocytes. More recently, a 35\% EBV positivity in 23 nasal polyps was found by qualitative PCR [19]; whereas in a study on nasal polyps and hypertrophied turbinates from Hong Kong patients, no specimen was positive to EBV in situ hybridization [20]. Taking into account also the different methods and particularly the absence of quantitative molecular data in previous studies, it could be argued that EBV positivity in polyps represents its presence in the inflammatory lymphoid tissue. This hypothesis could be further supported by the fact that EBV was detected at a lower rate in healthy tissue (turbinate mucosa) than in polyps, although the difference was not significant, and by the fact that viral load was always within an order of magnitude of $10^{2}$ copies $/ 10^{4}$ cells. Although EBV can persist in that lymphocytes can be infected by virus released from a lytic EBV infection in the nasal mucosa, the fact that EBV is detected in a high rate in normal nasopharyngeal mu- cosa tissue (up to $88 \%$ in some studies [18]), whereas nasal polyps are much rarer, argues against an EBV contribution to polyp development. This is further supported by data on viral load of the present study and the low number of EBV+ cells in each positive case described by Tao et al. [18].

Only one study investigated HHV-6 prevalence in polyps and inferior turbinates without finding any positive specimen [19]. This is in contrast to the present study in which HHV-6 was detected in $>35 \%$ of turbinate mucosa specimens and $>8 \%$ of nasal polyps. This difference could be due to the different methods: quantitative real-time PCR with high specificity and sensibility in the present study, traditional PCR with $70 \mathrm{bp}$ amplicon length in the study by Zaravinos et al. [19]. The relatively high HHV-6 prevalence in healthy tissues found in our study could be due to its frequent occurrence and diffusion in different tissues. HHV-6 seroprevalence is the highest amongst herpesviruses; furthermore, HHV -6 is the only herpesvirus which is able to integrate its DNA in the human genome, as it can be detectable in chromosomically integrated status in $0.2-$ $0.8 \%$ of the general population. Persistence of HHV-6 involves both a true latent state and a low-level chronic replication, each occurring at different anatomic sites, including nasal mucosa. It is to note that a possible limitation of this study is the lack of healthy controls, as well as of normal sinonasal specimens from patients with other underlying pathologies.

Furthermore, we evaluated the presence of CARVs using a multiplex PCR and found only one cytological sample positive to parainfluenza virus-1. These results are in accordance with a previous study on 13 sinonasal mucosa specimens from CRSwNP patients and 2 from healthy subjects that resulted negative to a panel of 12 CARVs [21]. Other authors evaluated the presence of picornaviruses in nasal washing and turbinate mucosa from 39 patients affected by CRSwNP and 27 healthy people and found a $21 \%$ rhinovirus positivity in patients, while no virus was found in controls [22]. A more recent study investigated CARVs in paranasal sinus mucosa and polyps by multiplex PCR and found a $18 \%$ positivity to bocavirus and $<2 \%$ positivity to rhinovirus in 102 tissue samples from 88 patients [23]. In the present study, the lack of CARVs detection in any specimen (but the cytological sample) seems to argue against a potential involvement of these viruses in this clinical context.

In conclusion, only EBV and HHV-6 were detected at certain frequency in nasal polyps and adjacent turbinate 
mucosa specimens, respectively, although with no statistical significance. To date, the data obtained by the present and other studies seem to argue against a definite role for herpesviruses and CARVs in the development of nasal polyps. Future studies should take into account the rela- tively higher frequency of EBV detection in polyps that could suggest a causative role in the formation of nasal polyps, as previously suggested by others, or EBV persistence in the inflammatory lymphoid tissue which characterizes these lesions.

\section{References}

1 Fokkens WJ, Lund VJ, Mullol J, Bachert C, Alobid I, Baroody F, Cohen N, Cervin A, Douglas R, Gevaert P, Georgalas C, Goossens H, Harvey R, Hellings P, Hopkins C, Jones N, Joos G, Kalogiera L, Kern B, Kowalski M, Price D, Riechelmann H, Schlosser R, Senior B, Thomas M, Toskala E, Voegels R, Wang DY, Wormald PJ: European Position Paper on Rhinosinusitis and Nasal Polyps 2012. Rhinology 2012;23(suppl):1-298.

-2 Badia L, Lund V: Topical corticosteroids in nasal polyposis. Drugs 2001;61:573-578.

-3 Yamada T, Fujieda S, Mori S, Yamamoto H, Saito H: Macrolide treatment decreased the size of nasal polyps and IL-8 levels in nasal lavage. Am J Rhinol 2000;14:143-148.

-4 Stammberger H: Endoscopic endonasal surgery - new concepts and treatment of recurring rhinosinusitis: I. Anatomic and pathophysiologic considerations; II. Surgical considerations. Otolaryngol Head Neck Surg 1986;94:143-156.

5 Zaravinos A, Bizakis J, Soufla G, Sourvinos G, Spandidos DA: Mutations and differential of the ras family genes in human nasal polyposis. Int J Oncol 2007;31:1051-1059.

6 Watelet JB, Claeys C, Perez-Novo C, Gevaert P. Van Cauwenberge P, Bachert C: Transforming growth factor- $\beta_{1}$ in nasal remodeling: differences between chronic rhinosinusitis and nasal polyposis. Am J Rhinol 2004; 18 : 267-272.

7 Zaravinos A, Soufla G, Bizakis J, Spandidos DA: Expression analysis of VEGFA, FGF2, TGF- $\beta_{1}$, EGF and IGF- 1 in human nasal polyposis. Oncol Rep 2008;19:385-391. $\checkmark 8$ Hamilos DL, Leung DY, Wood R, Meyers A, Stephens JK, Barkans J, Meng Q, Cunningham L, Bean DK, Kay AB, Hamid Q: Chronic hyperplastic sinusitis: association of tissue eosinophilia with mRNA expression of granulocyte-macrophage colony-stimulating factor and interleukin-3. J Allergy Clin Immunol 1993;92:39-48.

$>9$ Mygind N: Nasal polyposis. J Allergy Clin Immunol 1990;86:827-829.

10 Klemens JJ, Thomson K, Longerman A, Naclerio RM: Persistent inflammation and hyperresponsiveness following viral rhinosinusitis. Laryngoscope 2006;116:1236-1240.

-11 Stierna P, Carlsoo B: Histopathological observations in chronic maxillary sinusitis. Acta Otolaryngol (Stockh) 1996;116:316-321.

12 Hoffmann M, Klose N, Gottschlich S, Görögh T, Fazel A, Rittgen W, Ambrosch P, Schwarz E, Kahn T: Detection of human papillomavirus DNA in benign and malignant sinonasal neoplasms. Cancer Lett 2006;239:64-70.

13 Zhou Y, Hu M, Liu C: Human papillomavirus DNA test in nasal polyposis. Lin Chuang Er Bi Yan Hou Ke Za Zhi 2001;15:212-213.

$\checkmark 14$ Hoffmann M, Kahn T, Goeroegh T, Lohrey C, Gottshlich S, Meyer J, Rudert H, Maune S: Tracing human papillomavirus DNA in nasal polyps by polymerase chain reaction. Acta Otolaryngol 2000;120:872-875.

15 Lund VJ, Mackay IS: Staging in rhinosinusitis. Rhinology 1993;31:183-184.

16 Cheung WWY, Chan AC, Loke SL, Srivastava G, Pittaluga S, Lim LY, Ho FCS: Latent sites of Epstein-Barr virus infection. Am J Clin Pathol 1993;100:502-506.
17 Tao Q, Srivastava G, Chan ACL, Chung LP Loke SL, Ho FCS: Evidence for lytic infection of Epstein-Barr virus in mucosal lymphocytes instead of nasopharyngeal epithelial cells in normal individuals. J Med Virol 1995;45:7177.

18 Tao Q, Srivastava G, Dickens P, Ho FCS: Detection of Epstein-Barr virus-infected mucosal lymphocytes in nasal polyps. Am J Pathol 1996;149:1111-1118.

19 Zaravinos A, Bizakis J, Spandidos DA: Prevalence of human papilloma virus and human herpes virus types 1-7 in human nasal polyps. J Med Virol 2009;81:1613-1619.

20 Sham CL, To KF, Chan PK, Lee DL, Tong MC, van Hasselt CA: Prevalence of human papilloma virus, Epstein-Barr virus, p21, and p53 expression in sinonasal inverted papilloma, nasal polyp, and hypertrophied turbinate in Hong Kong patients. Head Neck 2012;34: 520-533.

21 Wood AJ, Antoszewska H, Fraser J, Douglas $\mathrm{RG}$ : Is chronic rhinosinusitis caused by persistent respiratory virus infection? Int Forum Allergy Rhinol 2011;1:95-100.

22 Jang YJ, Kwon HJ, Park HW, Lee BJ: Detection of rhinovirus in turbinate epithelial cells of chronic sinusitis. Am J Rhinol 2006;20: 634-636.

23 Falcone V, Ridder GJ, Panning M, Bierbaum S, Neumann-Haefelin D, Huzly D: Human bocavirus DNA in paranasal sinus mucosa. Emerg Infect Dis 2011;17:1564-1565. 